\title{
Use of SSR Markers to Assess Identity, Pedigree, and Diversity of Cultivated Muscadine Grapes
}

\author{
Summaira Riaz, Alan C. Tenscher, Brady P. Smith, Daniel A. Ng, and M. Andrew Walker ${ }^{1}$ \\ Department of Viticulture and Enology, University of California, Davis, CA 95616
}

Additional INDEX wORDs. Muscadinia rotundifolia, DNA fingerprinting, germplasm management, VR hybrids

\begin{abstract}
The North American muscadine grape (Muscadinia rotundifolia Small) is a valuable source of resistance to powdery mildew [Uncinula necator (Schw.) Burr], root-knot nematode (Meloidogyne Goeldi), dagger nematode (Xiphinema index Thorne and Allen), grape phylloxera (Daktulosphaira vitifoliae Fitch), and Pierce's disease (Xylella fastidiosa Wells et al.). Efforts to breed muscadine grapes commenced in the early 1900s and have generated a large number of cultivars and a limited number of hybrids with Vitis vinifera $\mathbf{L}$. and other Vitis $\mathbf{L}$. species. Collections of this germplasm are currently maintained with accession identity based on declared identity when collected, breeding records, and comparisons of morphological traits. This study reports on the first use of DNA-based simple sequence repeat (SSR) marker profiles to authenticate $M$. rotundifolia cultivars and hybrids. A total of 57 accessions [39 M. rotundifolia cultivars, 3 V. vinifera cultivars, 3 Vitis spp. hybrids, and 12 V. vinifera $\times M$. rotundifolia (VR) hybrids] from collections at the U.S. Department of Agriculture National Clonal Germplasm Repository and the University of California (Davis) Department of Viticulture and Enology were analyzed with 14 SSR markers. The fingerprint profiles were used to verify published breeding records of $31 \mathrm{M}$. rotundifolia cultivars and hybrids by comparing the shared alleles of parents and progeny. Marker data indicated that four cultivars were incorrectly identified; their alleles did not match respective parent/progeny relationships at more than five loci. Two $M$. rotundifolia accessions had the same fingerprint profile as a third accession at all 14 markers, implicating a likely planting error. The $M$. rotundifolia cultivars exhibited 88 unique alleles that were not present in a database of more than $600 \mathrm{~V}$. vinifera cultivars.
\end{abstract}

Muscadine grape is genetically and morphologically distinct from species within the genus Vitis. The most obvious genetic difference between these two taxa is the number of somatic chromosomes: Muscadinia Small species have 40, and Vitis species have 38. Muscadinia species also differ from Vitis species in their seed, bark, tendril, and cluster morphology. There is disagreement as to whether the differences between Muscadinia and Vitis warrant generic status (Olmo, 1995) or whether these taxa are best considered subgenera or sections (Liberty Hyde Bailey Horitorium, 1976). Muscadinia species possess very strong resistance to grape pests and diseases (Olmo, 1986), which prompted efforts to cross Muscadinia rotundifolia with Vitis vinifera cultivars. Although Vitis species hybridize freely, Vitis $\times$ Muscadinia crosses are difficult, and hybrids are rare and normally sterile, with 39 chromosomes.

Crop improvement within $M$. rotundifolia began with the selection of high-quality pistillate vines from within the native range (southeastern and south-central United States) of this dioecious species. Muscadine grapes were cultivated in the 16th century by European settlers, and they likely used high-quality forms selected by Native Americans before this date. 'Eden', 'Flowers', 'James', 'Memory', 'Mish', 'Scuppernong', and 'Thomas' are among the oldest cultivars and were all collected from the wild (Husmann and Dearing, 1913; Reimer and Detjen, 1914). Since then, there have been three primary objectives in muscadine breeding programs: 1) the development of hermaphroditic, self-fertile cultivars with enhanced

Received for publication 11 Dec. 2007. Accepted for publication 10 Apr. 2008. Funding for this project from the California Grape Rootstock Improvement Commission and the Louis P. Martini Endowed Chair funds is gratefully acknowledged. We also thank Gerald Dangl and Ed Stover for comments on this manuscript.

${ }^{1}$ Corresponding author. E-mail: awalker@ucdavis.edu. fruit quality and yields; 2) the introgression of $M$. rotundifolia into $V$. vinifera to develop disease-resistant fruiting cultivars with high-quality fruit; and 3) the utilization of $M$. rotundifolia in rootstock breeding. Dearing led the first large-scale muscadine breeding program in a cooperative effort between the U.S. Department of Agriculture-Agricultural Research Service (USDA-ARS) and North Carolina State University. He reported on the first self-fertile muscadine genotypes (Dearing, 1917), leading to a number of cultivar releases (Dearing, 1948). Muscadine breeding programs were also conducted in Mississippi, Georgia (Lane, 1980), and Florida (Bates et al., 1980; Mortensen, 1971).

Efforts to introgress disease and pest resistance from $M$. rotundifolia into $V$. vinifera or other Vitis species and hybrids were confounded by the differences in chromosome numbers and the sterility of the resulting hybrids. However, fertile $V$. vinifera $\times$ M. rotundifolia (VR) hybrids have been produced (Detjen, 1919; Olmo, 1986). One such hybrid, NC6-15, produced by Detjen, is the backbone of the powdery mildew disease resistance breeding program in France (Pauquet et al., 2001). Olmo (1986) was also able to create a few fertile VR hybrids, which continue to be used in the current grape breeding program at the University of California, Davis. Although VR hybrid fruiting cultivars have not been released, a VR hybrid, 'O39-16', was released as a rootstock for use in controlling fanleaf degeneration (Walker et al., 1991).

These breeding efforts have resulted in large collections of M. rotundifolia cultivars and VR hybrids. At present, accessions within these collections are documented by comparing breeding records and morphological traits. A molecular marker-based database to aid in establishing a reference collection or aid in authenticating accession identification does not exist. DNA-based molecular markers, particularly simple 
Table 1. Parentage and origin of the studied plant material. The flower type and fruit color was observed on plants in the National Clonal Germplasm Repository at Davis, CA (NCGR-Davis) or University of California, Davis, Department of Viticulture and Enology (UCD-VE). Genotypes are grouped in sets: A to F are linked to the parentage analysis in Fig. 1; G contains reference Vitis vinifera cultivars, hybrids known to be in the parentage of other tested accessions, and $V$. vinifera $\times$ Muscadinia rotundifolia (VR) hybrids that are being used in breeding programs at UCD and elsewhere; H contains $M$. rotundifolia accessions without parentage information; I consists of accessions whose simple sequence repeat fingerprints did not match known parentages.

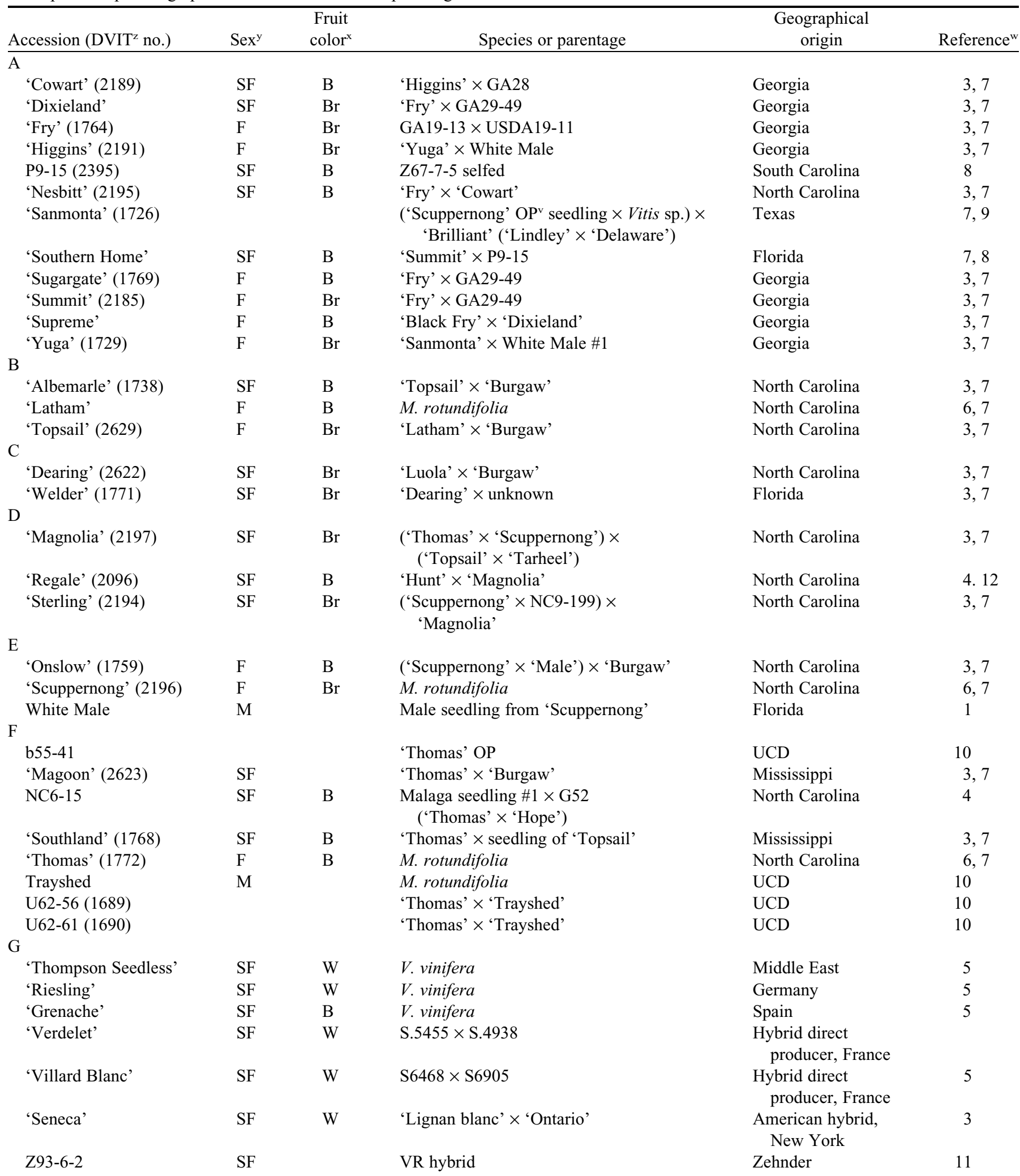


Table 1. Continued.

\begin{tabular}{|c|c|c|c|c|c|}
\hline Accession (DVIT ${ }^{z}$ no.) & $\operatorname{Sex}^{\mathrm{y}}$ & $\begin{array}{l}\text { Fruit } \\
\text { color }^{\mathrm{x}}\end{array}$ & Species or parentage & $\begin{array}{l}\text { Geographical } \\
\text { origin }\end{array}$ & Reference $^{w}$ \\
\hline Z97-60-3 & SF & & VR hybrid & Zehnder & 11 \\
\hline Z01-20-4 & & & VR hybrid & Zehnder & 11 \\
\hline NC194-1 & SF & $\mathrm{B}$ & $\begin{array}{l}\text { 'Seneca' } \times \text { M15 ['Thomas' } \times \text { NCB6-19 } \\
(\text { 'Latham' } \times \text { 'Burgaw')] }\end{array}$ & North Carolina & 2 \\
\hline JB81-107-11 & SF & $\mathrm{B}$ & $\begin{array}{l}\text { NC74C049-10 (UCD e4-12 (UCD Y14-14 } \\
\times \text { 'Grenache') } \times \text { M. rotundifolia } \\
\text { 'Magnolia') } \times \text { 'Verdelet' }\end{array}$ & North Carolina & 2 \\
\hline \multicolumn{6}{|l|}{$\mathrm{H}$} \\
\hline Barrett Mn-1 (2435) & & & Muscadinia munsoniana & $\mathrm{UCD}$ & 10 \\
\hline 'Pride' (1766) & $\mathrm{F}$ & B & GA19-13 × USDA19-11 & Georgia & 3,7 \\
\hline 'Tarheel' (1728) & SF & $\mathrm{B}$ & 'Luola' $\times($ 'Eden' $\times$ V23R4B2) & North Carolina & 3,7 \\
\hline Thornhill & & & M. munsoniana & Florida & 1 \\
\hline \multicolumn{6}{|l|}{ I } \\
\hline 'Creswell' (1746) & M & & M. rotundifolia & North Carolina & 3,7 \\
\hline Farrer F2 \#5 (1730) & $\mathrm{F}$ & B & NC6-15 OP & Georgia & 10 \\
\hline 'Irene' (1751) & M & & 'Thomas' $\times$ Black male & Georgia & 3,7 \\
\hline 'Jumbo' (2188) & $\mathrm{F}$ & $\mathrm{B}$ & 'Higgins' $\times$ USDA19-11 & Georgia & 3,7 \\
\hline 'Triumph' (2183) & SF & $\mathrm{Br}$ & 'Fry' × GA29-49 & Georgia & 3,7 \\
\hline
\end{tabular}

${ }^{\mathrm{z} D V I T}$ numbers are accession numbers for Vitis in NCGR-Davis.

${ }^{y} \mathrm{SF}=$ self-fertile, $\mathrm{F}=$ pistillate, $\mathrm{M}=$ staminate.

${ }^{\mathrm{x}} \mathrm{B}=$ black to dark purple, $\mathrm{W}=$ green to white, $\mathrm{Br}=$ bronze.

${ }^{\mathrm{w}} 1=$ H.C. Barrett breeding records; $2=$ J.P. Bloodworth breeding records; $3=$ Brooks and Olmo, 1997; $4=$ Detjen, $1919 ; 5=$ Galet, $1998 ; 6=$ Husmann and Dearing, 1913; 7 = Mortensen, 2001; $8=$ Mortensen et al., 1994; $9=$ Munson, 1909; $10=$ H.P. Olmo breeding records; $11=$ D.W. Ramming breeding records.

${ }^{\mathrm{v}}$ Open pollinated.

sequence repeat (SSR) markers, are excellent fingerprinting tools and have been used to identify grape cultivars and to assist in the maintenance of grape germplasm collections (Dangl et al., 2001; Thomas et al., 1994). The study presented here reports on the first use of SSR markers to manage $M$. rotundifolia germplasm. The resulting fingerprint profiles from 14 SSR markers were used to verify reported pedigrees and to assess the genetic diversity of muscadine cultivars.

\section{Materials and Methods}

Plant material. Table 1 presents the parentage, geographic origin of the M. rotundifolia cultivars, breeder selections, and hybrids studied. A few $V$. vinifera cultivars were also included to act as allele size references for comparison with other fingerprint databases. All plant material with a DVIT (DavisVitis) number is maintained at the USDA National Clonal Germplasm Repository, Davis, CA (NCGR-D). The remaining accessions are maintained in breeding blocks at the Department of Viticulture and Enology, University of California, Davis (UCD-VE).

DNA ISOLATION AND MICROSATELLITE GENOTYPING. DNA was extracted from young leaves and shoot tips using a modified hexadecyltrimethylammonium bromide procedure as described by Lodhi et al. (1994). In cases where actively growing shoot tips and young leaves were not available, DNA was extracted from shoot cambium tissue. A total of 20 SSR markers selected from 11 different linkage groups from the Vitis rupestris Scheele $\times$ Vitis arizonica Engelm. genetic map (Riaz et al., 2006) was used to establish DNA profiles for the each of the tested accessions (Table 2). The sequences of primers were obtained from previous published studies: VVS2 (Thomas et al., 1994); VVMD07 and VVMD27 (Bowers et al., 1996, 1999); VrZAG62 (Sefc et al., 1999); VMC4f3.1 (Di Gaspero et al., 2000); VMC8b5 (Adam-Blondon et al., 2004); and VVIN16 (Merdinoglu et al., 2005). The Vitis Microsatellite Consortium (VMC) primer sequences are available on National Center for Biotechnology Information (NCBI) uni-STS (unified sequence tagged sites) database for Vitis (NCBI, 2005) and from publicly available expressed sequence tagged (EST)derived microsatellites developed by D.R. Cook (Department of Plant Pathology, University of California, Davis), which are available at the Core Genome Facility (CGF; University of California, 2003). The conditions for marker amplification were previously described in Riaz et al. (2004), except that the amount of reaction mixture was reduced from 20 to $10 \mu \mathrm{L}$. The amplified products were separated on denaturing $5 \%$ polyacrylamide sequencing gels and were visualized by silver 
Table 2. Marker name and linkage group location as determined from the Vitis vinifera reference map (Doligez et al., 2006), amplification status in Muscadinia, and references for the markers used in this study.

\begin{tabular}{lcll}
\hline & $\begin{array}{c}\text { Linkage } \\
\text { group } \\
\text { no. }\end{array}$ & Amplified & \multicolumn{1}{c}{ Reference $^{z}$} \\
\hline VVMD27 & 5 & Yes & Bowers et al., 1999 \\
VVMD7 & 7 & Yes & Bowers et al., 1996 \\
VrZAG62 & 7 & Yes & Sefc et al., 1999 \\
VMC5h2 & 8 & Yes & NCBI, 2005 \\
VMC5c1 & 9 & Yes & NCBI, 2005 \\
VMC3d7 & 10 & Yes & NCBI, 2005 \\
VVS2 & 11 & Yes & Thomas and Scott, 1994 \\
VMC8g9 & 12 & Yes & NCBI, 2005 \\
VMC4f3.1 & 12 & Yes & Di Gaspero et al., 2000 \\
VMC1g3.2 & 12 & No & Di Gaspero et al., 2000 \\
VMCNg2h7 & 12 & Multiple & Di Gaspero et al., 2000 \\
& & loci & \\
ctg1010863 & 12 & No & University of California, 2003 \\
VMC2b1.1 & 18 & No & University of California, 2003 \\
VMC2a3 & 18 & No & University of California, 2003 \\
VMC8b5 & 18 & No & Adam-Blondon et al., 2004 \\
VVIN16 & 18 & Yes & Meridinoglu et al., 2005 \\
VMC6e1 & 14 & Yes & NCBI 2005 \\
VMC2a5 & 14 & Yes & NCBI, 2005 \\
VMC5a1 & 16 & Yes & NCBI, 2005 \\
VMCNg3a10 & 19 & Yes & Unpublished \\
\hline NCBI $=$ Nation & & &
\end{tabular}

${ }^{\mathrm{z}} \mathrm{NCBI}=$ National Center for Biotechnology Information.

staining with a commercial kit (Promega, Madison, WI). Useful markers were amplified, run on polyacrylamide gels, and scored twice. Allele sizes in base pairs were determined by direct comparison with a sequencing reaction (Promega) run on each gel, as well as by comparisons to three common $V$. vinifera cultivars included in the study set. All gels were visually examined and scored on a light box and were then digitally scanned to preserve the images.

Data analysis. To verify the published parentage and identity of the M. rotundifolia cultivars, allele size data were subjected to several analyses for polymorphic SSR markers with the assumption that there were no mistakes in the identity of genotypes in the collections. Expected heterozygosity $\left(H_{\mathrm{e}}\right)$ was calculated according to Nei (1987), using the microsatellite tool kit software (Park, 2001), which was also used to calculate allele frequencies. Observed heterozygosity was calculated as the ratio between heterozygous genotypes and the total number of genotypes analyzed for each marker. Pairwise similarity between the multilocus genotypes was estimated by using the "proportion of shared alleles" (ps) as described by Bowcock et al. (1994). The $-\ln$ (ps) option of MICROSAT, version 2.0 (Minch, 1997), was used to calculate the genetic distance between all pairwise combinations of the 57 genotypes with 14 SSR markers. The ps statistic is a measure of the dissimilarity between two samples. Thus, two individuals that are identical at all tested loci would have zero distance between them. A dendrogram was constructed with the unweighted pair-group method with arithmetic means (UPGMA) algorithm (Sneath and Sokal, 1973) using PHYLIP software, version 3.6 (Felsenstein, 2006), for the estimation. TreeView (Page, 1996) was used to construct the dendrogram.

\section{Results}

SSR MARKER AMPLIFICATION. Nineteen SSR markers used in this study were developed from repeat-rich genomic libraries made from nuclear DNA of $V$. vinifera and Vitis riparia $\mathrm{L}$. cultivars. The 20th marker, ctg1010863, is an EST-derived SSR marker from $V$. vinifera (Table 2). No M. rotundifolia-based SSR or EST-SSR markers are available in public databases. Table 2 also presents the linkage group (LG) location of the 20 SSR markers tested. Five markers from LG12 and four markers from LG18 were selected because these two LGs are reported to harbor disease resistance genes for fungal diseases. Markers VMC8g9, VMC1g3.2, and VMC4f3.1 from LG12 have been linked to powdery mildew resistance and have been used to screen VR hybrid mapping populations segregating for powdery mildew resistance (Barker et al., 2005). Three of the nine markers from LG12 and 18 amplified successfully (two from LG12 and one from LG18; Table 2). The remaining six markers (VMC1g3.2, VMCNg2h7, ctg1010863, VMC8b5, VMC2a3, and VMC2b1.1) failed to amplify $M$. rotundifolia genomic DNA or amplified multiple loci, however, these markers amplified $V$. vinifera-based DNA successfully. Eleven markers from nine other linkage groups amplified successfully and resulted in a high level of polymorphism across the $M$. rotundifolia cultivars (Tables 2, 3, and 4). Table 4 presents the genotyping data for the entire study set.

AFFiRMation OF PARENT-PROGENY RELATIONSHIPS TO VERIFY M. ROTUNDIFOLIA CULTIVAR IDENTITY. First order parentage analysis (one common allele between putative parent-progeny pairs for all markers) was carried out with data from the 14 polymorphic markers. An error in accession identification or reported pedigree was assumed when a purported parentprogeny pair did not share a common allele at every marker. Figure 1 presents the parent-progeny relationships that were consistent across all 14 markers (i.e., progeny had shared alleles from specified parents). In this way, allele comparisons were

Table 3. Genetic parameters of SSR markers, with number of alleles detected across all studied accessions (those unique to Muscadinia are listed in Table 5), and the observed and expected heterozygosity for 35 verified Muscadinia accessions.

\begin{tabular}{lccc}
\hline Locus name & $\begin{array}{c}\text { Alleles } \\
\text { detected } \\
\text { (no.) }\end{array}$ & $\begin{array}{c}\text { Observed } \\
\text { heterozygosity } \\
(\%)\end{array}$ & $\begin{array}{c}\text { Expected } \\
\text { heterozygosity } \\
(\%)\end{array}$ \\
\hline VVMD27 & 16 & 0.81 & 0.78 \\
VVMD07 & 11 & 0.77 & 0.75 \\
VrZAG62 & 12 & 0.62 & 0.63 \\
VMC5h2 & 15 & 0.77 & 0.77 \\
VMC5c1 & 15 & 0.82 & 0.74 \\
VMC3d7 & 13 & 0.94 & 0.74 \\
VVS02 & 14 & 0.91 & 0.80 \\
VMC4f3.1 & 19 & 0.88 & 0.74 \\
VMC8g9 & 15 & 0.94 & 0.68 \\
VMC2a5 & 11 & 0.77 & 0.72 \\
VMC6e1 & 12 & 0.66 & 0.74 \\
VMC5a1 & 10 & 0.77 & 0.73 \\
VVIN16 & 5 & 0.05 & 0.05 \\
VMCNg3a10 & 16 & 0.94 & 0.85 \\
Total & 184 & 10.65 & 9.72 \\
Avg no./locus & 13 & 0.76 & 0.69 \\
\hline
\end{tabular}




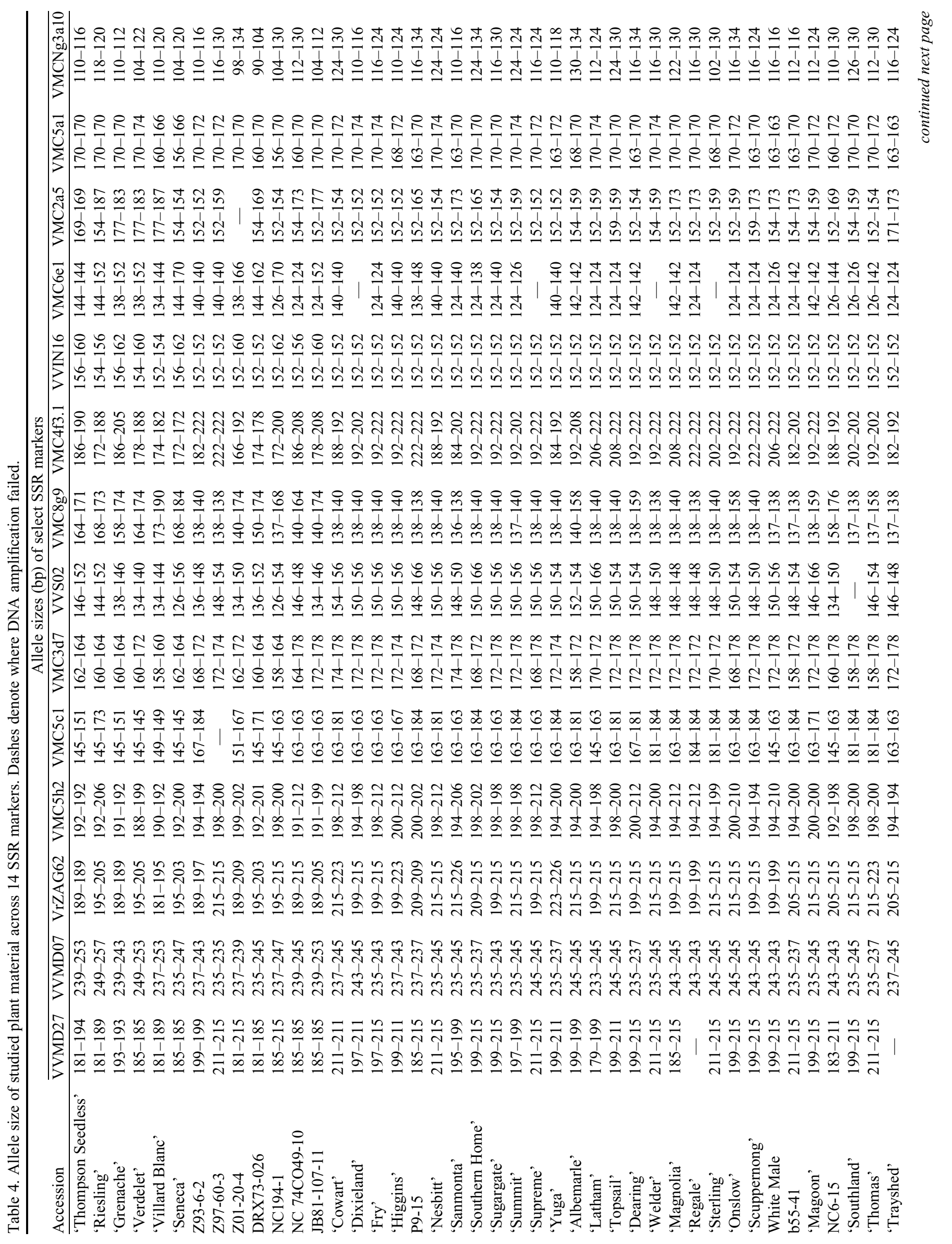




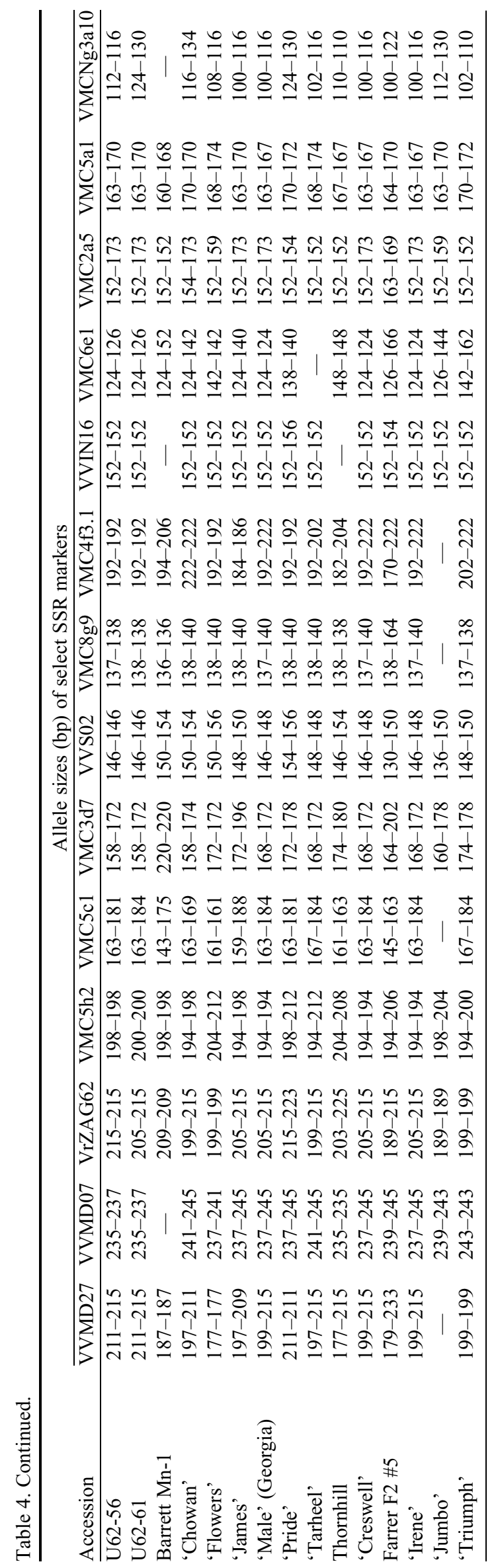

shown to support the designated identities of $30 \mathrm{M}$. rotundifolia cultivars and hybrids (Fig. 1). The profiles of four M. rotundifolia accessions, White Male, 'Jumbo', 'Triumph', and Farrer F2 \#5 were not consistent with published pedigree records (Table 1).

Breeding records report that White Male is a male seedling of 'Scuppernong', and SSR data indicate that it shares one allele with the NCGR-D 'Scuppernong' at all amplified markers (data not shown). White Male is also reported to be in the pedigree of 'Higgins' and 'Yuga', yet White Male did not share alleles with 'Higgins' or 'Yuga' at five and seven markers, respectively (allele size data not shown). This observation indicates that White Male in the UCD-VE collection is not the accession reportedly used to generate 'Higgins' and 'Yuga'. It is important to point out that the name White Male is purely descriptive and may have been used for different genotypes. It is also possible that multiple collections have accessions with the same name, but different genetic profiles. The accession 'Jumbo' was not closely related to its reported parent 'Higgins' (Brooks and Olmo, 1997), but it was closely related to the VR hybrid 'NC6-15' (Fig. 2). Similarly 'Triumph' did not share alleles with its reported parent 'Fry' (Brooks and Olmo, 1997). Patel and Olmo (1955) reported that Farrer F2 \#5 originated from an open pollinated NC6-15 cluster and that it has 39 chromosomes. However, the NCGR-D Farrer F2 \#5 has a very unique allelic profile that did not group closely with any other genotype, and it was more closely related to $M$. rotundifolia than to $V$. vinifera or the other VR hybrids (Fig. 2).

Two M. rotundifolia cultivars, 'Creswell' and 'Irene', matched each other and also matched 'Male' (Georgia) at all 14 markers. Breeding records indicate that 'Creswell' and 'Irene' have pistillate flowers. However, both of these genotypes have staminate flowers at the NCGR-D, indicating that a mistake was made during the original importation or subsequent replanting and the same genotype was planted with different names. These three cultivars also grouped together in the UPGMA-based dendrogram (Fig. 2). Comparisons could not be made for 12 other $M$. rotundifolia cultivars and hybrids because potential parents and progeny were not part of the study set.

The validation of 'Thomas' as a grandparent of the VR hybrid NC6-15 was an important result given its current use in breeding for powdery mildew resistance (Pauquet et al., 2001). Detjen (1919) made the $V$. vinifera Malaga seedling $\# 1 \times M$. rotundifolia G52 ('Thomas' $\times$ 'Hope') cross to produce NC615 (Table 1). Reimer and Detjen (1914) described 'Hope' as the first recorded $M$. rotundifolia hermaphrodite, but noted that it was incapable of producing viable seed. 'Hope' does not exist in the NCGR-D or UCD-VE collections. The genotype G52 may have been lost when the North Carolina State breeding program was discontinued during the U.S. Prohibition era, and no other copy is listed in the national or international collection records. The cultivar Thomas is the only link available to the powdery mildew-resistant selection NC6-15. Therefore, the verifying the correct identity of 'Thomas' is critical. 'Thomas' has been used as a parent in breeding to develop hybrid $M$. rotundifolia cultivars (Fig. 1, section F). In four of the reported cases, 'Thomas' shares one allele at all loci examined to the respective progeny, suggesting that the NCGR-D holds the correct 'Thomas' accession. Moreover, 'Thomas' as a grandparent of NC6-15 should share one-quarter of its alleles with 
(A)

(B)

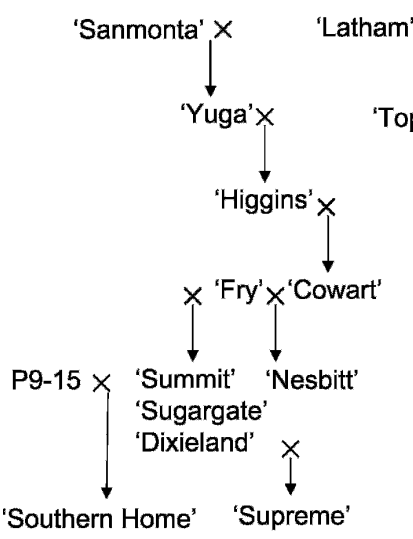

'Southern Home' 'Supreme'
(C)

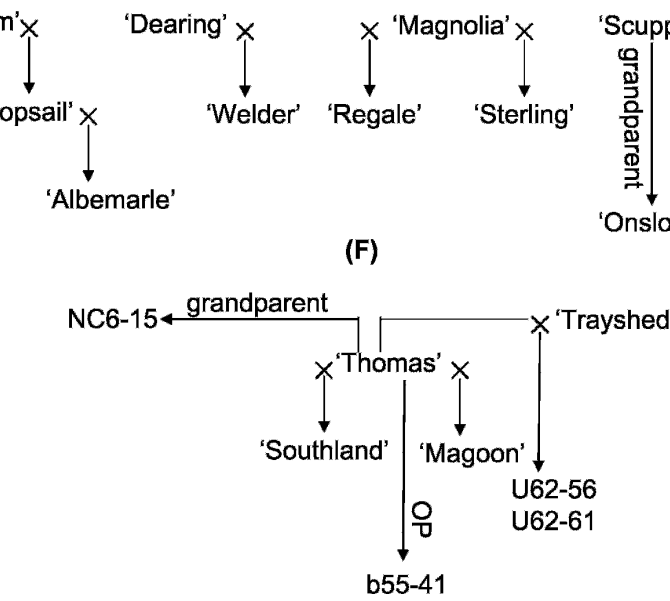

(E)

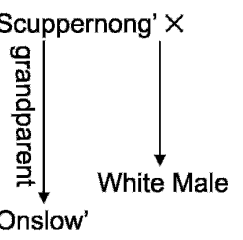

folia, further emphasizing the differences in allelic composition of this species (Table 5).

The genetic similarity of $M$. rotundifolia cultivars and VR hybrids was also analyzed using genetic distance analysis (Fig. 2). Four VR hybrids (NC74-10, JB81107-11, NC194-1, and DRX73026) clustered with $V$. vinifera accessions and grouped separately from all other genotypes. The accessions Farrer F2 \#5, Thornhill, and Barrett $\mathrm{Mn}-1$ were outliers. Thornhill and BarrettMn-1 are Muscadinia munsoniana (Simpson) Small accessions that were collected from Florida. As noted above, Farrer F2 \#5 did not match its published parentage. The $M$. rotundifolia cultivars were clustered in small groups with common

Fig. 1. Diagram of six partial pedigrees (A through F) where published parental relationships of Muscadinia rotundifolia cultivars could be confirmed with SSR marker data, See Table 4 for complete marker data; OP = open pollinated.

NC6-15. They had one common allele at 11 of 14 studied markers, which is consistent with 'Thomas' being a grandparent of NC6-15.

GeNETIC DIVERSITY OF CULTIVATED M. RotUNDIFolia. The allelic distribution and allele frequency were analyzed with SSR markers. The distribution analysis was carried out within $M$. rotundifolia cultivars, VR hybrids, and with selected $V$. vinifera cultivars and selections that are in the background of VR hybrids to determine the specificity and frequency of alleles unique to $M$. rotundifolia cultivars. A total of 184 alleles was detected in the 57 genotypes with an average of 13 alleles per marker (Table 3). The average observed heterozygosity of SSR markers was slightly higher for the complete set of 57 genotypes (all $V$. vinifera cultivars, VR hybrids, and $M$. rotundifolia cultivars) when compared with the set composed only of 35 pure $M$. rotundifolia cultivars, but the difference was not significant (results not shown). The difference between the observed and expected heterozygosity values for the $M$. rotundifolia cultivars was also small (Table 3). For 10 of the studied markers, observed heterozygosity was higher than expected, indicating that the studied set of $M$. rotundifolia cultivars is diverse and there is no indication of inbreeding depression (Table 3). For four markers (VVMD27, VVMD7, VrZAG62, and VVS2), alleles were also compared with a database of more than $600 \mathrm{~V}$. vinifera-based cultivars to identify $M$. rotundifolia-specific alleles (G. Dangl, personal communication). However, it is important to note that Vitis and Muscadinia can have alleles of the same size (base pairs) and still have a unique origin. Only six alleles from four of the compared markers were common to the $V$. vinifera cultivars (Table 5). The comparisons found important differences in $M$. rotundifolia allelic composition reflected by the existence of a unique set of alleles with different frequencies. There were 88 unique $M$. rotundifolia alleles (Table 5). Within the studied set, eight alleles from eight markers had frequencies higher than 30.0 (VrZAG62-215, VMC5c1-163, VMC3d7-172, VMC8g9138, VMC2a5-152, VMC6e1-124, VMC5a1-170, and VVIN16-152), whereas 47 alleles were present at frequencies lower than 1.0. It is also worth noting that the alleles with higher frequency at six of eight markers were unique to $M$. rotundi-

genetic backgrounds (Fig. 2), further validating the breeding records.

\section{Discussion}

Confirming the identity of grape cultivars based on comparisons with their published morphological traits is difficult. The environment can alter the expression of morphological traits, and identification is further complicated by record-keeping mistakes and propagation errors. Molecular markers like SSRs are ideal tools to differentiate cultivars, to determine phylogeographic structure of wild grapevines for conservation biology, to determine parent-progeny relationships, to identify grapevine accessions, to decipher homonyms and synonyms in grapevine cultivars, and to develop genetic maps of $V$. vinifera and Vitis species (Aradhya et al., 2003; Bowers et al., 1999; Dangl et al., 2001; Doligez et al., 2006; Lowe and Walker, 2006; Riaz et al., 2004, 2006). Thus, the use of SSR markers is invaluable in managing germplasm collections.

Many $V$. vinifera- and $V$. riparia-based SSR markers have been developed and have been shown to amplify sequences for other Vitis species (Sefc et al., 1999). However, the use of Vitisbased SSR markers to manage collections of $M$. rotundifolia cultivars and hybrids has not been reported. This study used SSR markers to evaluate the identity of the M. rotundifolia cultivars and hybrids maintained at the NCGR-D and UCD-VE collections. It was also intended to stimulate the use of SSR markers in other muscadine collections so that reference standards for identification can be agreed upon and the genetic diversity of $M$. rotundifolia germplasm can be maintained.

Fourteen SSR markers from 11 different linkage groups amplified $M$. rotundifolia DNA successfully, indicating that M. rotundifolia has a high degree of homology to Vitis species even though the chromosome number of the two genera is different. However, six markers from LG12 and 18 that have been previously mapped in a $V$. rupestris $\times V$. arizonica background (Riaz et al., 2006) did not amplify M. rotundifolia alleles or resulted in multiple loci, indicating that the genetic sequences of these LGs are different between Vitis and Muscadinia. The powdery mildew resistance gene Runl 


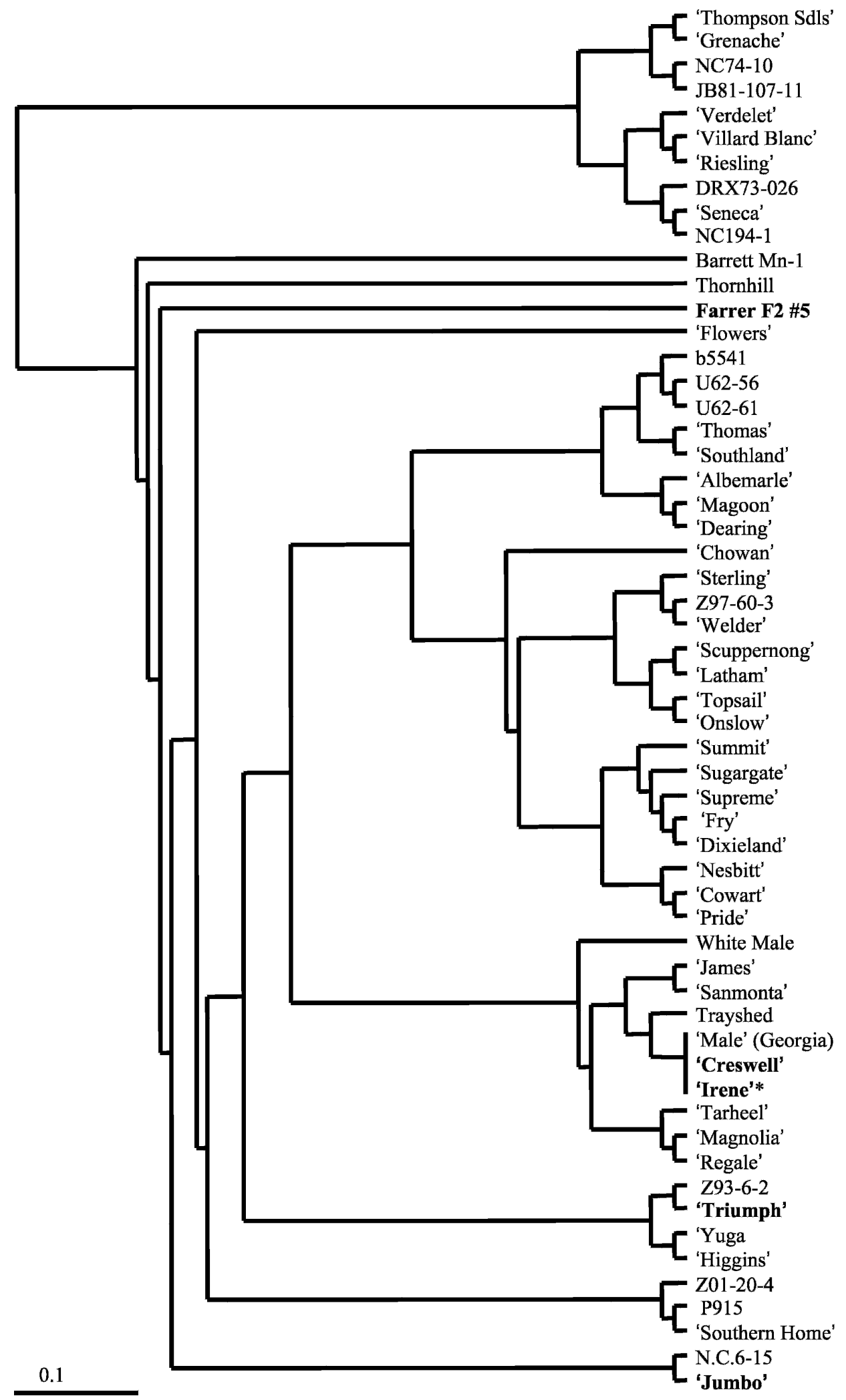

Fig. 2. Dendrogram displaying relationships among 57 grape accessions (Vitis vinifera, . vinifera $\times$ Muscadinia rotundifolia hybrids, and $M$. rotundifolia accessions) based on cluster analysis (UPGMA) of genetic dissimilarity estimated using the $[-\ln (\mathrm{ps})]$ transformation of the proportion of the shared alleles (ps). Accessions in bold print did not match expected relationships. Scale bar represents 0.1 nucleotide substitutions per site. has been genetically mapped on LG12 in populations that have NC6-15 in their background (Pauquet et al., 2001). Barker et al. (2005) reported that the physical map of Runl locus spans $450 \mathrm{~kb}$ with major gaps (i.e., the BAC contigs could not be extended), has extremely low recombination in vicinity of the resistance locus, and contains two different families of resistance gene analogs (RGA). Interestingly, Di Gaspero et al. (2007) reported that more than $50 \%$ of RGA markers mapped to LG12 and LG18. Although powdery mildew resistance from NC615 seems to segregate as a single dominant gene (Pauquet et al., 2001), the nature of this resistance is likely more complex given that powdery mildew resistance is controlled by multiple genes and alleles in other crop species $(\mathrm{Cal}-$ enge and Durel, 2006; Tommasini et al., 2006). Regardless of how powdery mildew resistance from $M$. rotundifolia is inherited, more information on the genetics of this resistance and how it functions under different environmental conditions is essential for it to be efficiently used in breeding programs.

Eighty-eight SSR alleles were unique to $M$. rotundifolia cultivars, indicating that the genome of $M$. rotundifolia is different from that of $V$. vinifera and consists of different sets of frequent alleles (Table 5). Genetic divergence between $M$. rotundifolia and $V$. vinifera was also supported by the analysis of genetic distance based on the proportion of shared alleles. The proportion of shared allele analysis makes no assumptions about the population under study or the frequency of alleles within a population. It has been used to construct trees of human individuals that reflected their ancestral origin with remarkable accuracy (Bowcock et al., 1994). A dendrogram depicting relatedness in the tested germplasm placed the M. rotundifolia cultivars in one large group and placed the $V$. vinifera accessions and the VR hybrids in a separate group (Fig. 2 ). The subgroupings of M. rotundifolia cultivars reflected their reported pedigrees. 
Table 5. Recorded allele sizes (AS) and allele frequencies (AF) for 14 SSR markers evaluated across 57 accessions. Alleles in bold font were unique to Muscadinia rotundifolia. Underlined alleles were present in other Vitis vinifera accessions that were not part of this studied set (G. Dangl, personal communication).

\begin{tabular}{|c|c|c|c|c|c|c|c|c|c|c|c|c|c|}
\hline \multicolumn{2}{|c|}{ VVMD27 } & \multicolumn{2}{|c|}{ VVMD7 } & \multicolumn{2}{|c|}{ VrZAG62 } & \multicolumn{2}{|c|}{ VMC5h2 } & \multicolumn{2}{|c|}{ VMC5c1 } & \multicolumn{2}{|c|}{ VMC3d7 } & \multicolumn{2}{|c|}{ VVS2 } \\
\hline$\overline{\mathrm{AS}}(\mathrm{bp})$ & $\overline{\mathrm{AF}}(\%)$ & $\overline{\mathrm{AS}}(\mathrm{bp})$ & $\overline{\mathrm{AF}(\%)}$ & $\overline{\mathrm{AS}(\mathrm{BP})}$ & $\overline{\mathrm{AF}(\%)}$ & $\overline{\mathrm{AS}}(\mathrm{bp})$ & $\overline{\mathrm{AF}}(\%)$ & $\overline{\mathrm{AS}}(\mathrm{bp})$ & $\overline{\mathrm{AF}}(\%)$ & $\overline{\mathrm{AS}}(\mathrm{bp})$ & $\overline{\mathrm{AF}}(\%)$ & $\overline{\mathrm{AS}}(\mathrm{bp})$ & $\overline{\mathrm{AF}(\%)}$ \\
\hline 177 & 2.78 & 233 & 0.89 & 181 & 0.88 & 188 & 0.88 & 143 & 0.91 & 158 & 7.89 & 126 & 1.79 \\
\hline 179 & 1.85 & $\overline{235}$ & 18.75 & 189 & 8.77 & 190 & 0.88 & 145 & 12.04 & 160 & 6.14 & 130 & 0.89 \\
\hline 181 & 4.63 & 237 & 19.64 & 195 & 5.26 & 191 & 2.63 & 149 & 1.85 & 162 & 2.63 & 134 & 4.46 \\
\hline 183 & 0.93 & 239 & 6.25 & 197 & 0.88 & 192 & 7.02 & 151 & 2.78 & 164 & 7.02 & 136 & 2.68 \\
\hline 185 & 11.11 & 241 & 2.68 & $\overline{199}$ & 17.54 & 194 & 24.56 & 159 & 0.91 & 168 & 7.89 & $\overline{138}$ & 0.89 \\
\hline 187 & 1.85 & 243 & 14.29 & 203 & 2.63 & 198 & 21.93 & 161 & 2.78 & 170 & 1.75 & 140 & 0.89 \\
\hline 189 & 1.85 & 245 & 28.57 & 205 & 9.65 & 199 & 3.51 & 163 & 38.89 & 172 & 33.33 & 144 & 1.79 \\
\hline 193 & 1.85 & 247 & 1.79 & 209 & 5.26 & 200 & 16.67 & 167 & 5.56 & 174 & 7.89 & 146 & 11.61 \\
\hline 194 & 0.93 & 249 & 1.79 & 215 & 42.11 & 201 & 0.88 & 169 & 0.93 & 178 & 21.05 & 148 & 20.54 \\
\hline 195 & 0.93 & 253 & 3.57 & 223 & 4.39 & 202 & 2.63 & 171 & 1.85 & 180 & 0.88 & $\overline{150}$ & 24.11 \\
\hline 197 & 5.56 & 257 & 0.89 & 225 & 0.88 & 204 & 2.63 & 173 & 0.91 & 196 & 0.88 & $\overline{152}$ & 3.57 \\
\hline 199 & 21.30 & & & 226 & 1.75 & 206 & 2.63 & 175 & 0.91 & 202 & 0.88 & 154 & 12.50 \\
\hline 209 & 0.93 & & & & & 208 & 0.88 & 181 & 10.19 & 220 & 1.75 & 156 & 10.71 \\
\hline 211 & 17.59 & & & & & 210 & 1.75 & 184 & 19.09 & & & 166 & 3.57 \\
\hline 215 & 25.00 & & & & & 212 & 10.53 & 188 & 0.91 & & & & \\
\hline 233 & 0.93 & & & & & & & & & & & & \\
\hline \multicolumn{2}{|c|}{ VMC4f3.1 } & \multicolumn{2}{|c|}{ VMC8g9 } & \multicolumn{2}{|c|}{ VMC2a5 } & \multicolumn{2}{|c|}{ VMC6e1 } & \multicolumn{2}{|c|}{ VMC5a1 } & \multicolumn{2}{|c|}{ VVIN16 } & \multicolumn{2}{|c|}{ VMCNg3a10 } \\
\hline AS (bp) & $\mathrm{AF}(\%)$ & AS (bp) & $\mathrm{AF}(\%)$ & $\overline{\mathrm{AS}(\mathrm{BP})}$ & $\mathrm{AF}(\%)$ & AS (bp) & $\mathrm{AF}(\%)$ & AS (bp) & $\mathrm{AF}(\%)$ & AS (Bp) & $\mathrm{AF}(\%)$ & AS (bp) & $\mathrm{AF}(\%)$ \\
\hline 166 & 0.89 & 136 & 2.68 & 152 & 41.96 & 124 & 32.69 & 156 & 1.75 & 152 & 84.55 & 90 & 0.89 \\
\hline 170 & 0.89 & 137 & 10.71 & 154 & 16.96 & 126 & 10.58 & 160 & 4.39 & 154 & 3.64 & 98 & 0.89 \\
\hline 172 & 3.57 & 138 & 36.61 & 159 & 11.61 & 134 & 0.96 & 163 & 14.91 & 156 & 5.45 & 100 & 3.57 \\
\hline 174 & 1.79 & 140 & 25.00 & 163 & 0.89 & 138 & 5.77 & 164 & 0.88 & 160 & 3.64 & 102 & 3.57 \\
\hline 178 & 2.68 & 150 & 0.89 & 165 & 1.79 & 140 & 15.38 & 166 & 1.75 & 162 & 2.73 & 104 & 4.46 \\
\hline 182 & 4.46 & 158 & 6.25 & 169 & 5.36 & 142 & 13.46 & 167 & 4.39 & & & 108 & 0.89 \\
\hline 184 & 2.68 & 159 & 1.79 & 171 & 2.68 & 144 & 7.69 & 168 & 5.26 & & & 110 & 10.71 \\
\hline 186 & 3.57 & 164 & 3.57 & 173 & 11.61 & 148 & 2.88 & 170 & 48.25 & & & 112 & 8.04 \\
\hline 188 & 4.46 & 168 & 2.68 & 177 & 3.57 & 152 & 4.81 & 172 & 10.53 & & & 116 & 23.21 \\
\hline 190 & 0.89 & 171 & 0.89 & 183 & 1.79 & 162 & 1.92 & 174 & 7.89 & & & 118 & 1.79 \\
\hline 192 & 27.68 & 173 & 1.79 & 187 & 1.79 & 166 & 1.92 & & & & & 120 & 2.68 \\
\hline 194 & 0.89 & 174 & 4.46 & & & 170 & 1.92 & & & & & 122 & 2.68 \\
\hline 200 & 0.89 & 176 & 0.89 & & & & & & & & & 124 & 14.29 \\
\hline 202 & 8.93 & 184 & 0.89 & & & & & & & & & 126 & 0.89 \\
\hline 204 & 0.89 & 190 & 0.89 & & & & & & & & & 130 & 15.18 \\
\hline 205 & 0.89 & & & & & & & & & & & 134 & 6.25 \\
\hline 206 & 2.68 & & & & & & & & & & & & \\
\hline 208 & 4.46 & & & & & & & & & & & & \\
\hline 222 & 26.79 & & & & & & & & & & & & \\
\hline
\end{tabular}

There were a relatively high number of alleles that were unique to $M$. rotundifolia cultivars when compared with those found in $V$. vinifera. However, these alleles were common across the group of $M$. rotundifolia cultivars, suggesting that the genetic base of these cultivars is limited. The wild populations of $M$. rotundifolia in the south-central and southeastern United States are a valuable source of germplasm with high resistance to many pests and diseases. Further study of wild M. rotundifolia populations is needed to clarify the nature and extent of their genetic and phylogeographic diversity. Wild populations of $M$. rotundifolia are not facing extinction, but their native growing areas are under increased human population pressure that could eventually lead to the erosion of natural genetic divergence in wild $M$. rotundifolia.

\section{Literature Cited}

Adam-Blondon, A.-F., C. Roux, D. Claux, G. Butterlin, D. Merdinoglu, and P. This. 2004. Mapping 245 SSR markers on the Vitis vinifera genome: A tool for grape genetics. Theor. Appl. Genet. 109:1017-1027.

Aradhya, M.K., G.S. Dangl, B.H. Prins, J.-M. Bourisquot, M.A. Walker, C.P. Meredith, and C.J. Simon. 2003. Genetic structure and differentiation in cultivated grape, Vitis vinifera L. Genet. Res. 81:179-192.

Barker, C.L., T. Donald, J. Pauquet, M.B. Ratnaparkhe, A. Bouquet, A.-F. Adam-Blondon, M.R. Thomas, and I. Dry. 2005. Genetic and physical mapping of the grape powdery mildew resistance gene, Run1, using a bacterial artificial chromosome library. Theor. Appl. Genet. 111:370-377.

Bates, R.P., J.A. Mortensen, and T.E. Crocker. 1980. Florida grapes: The next decade. Proc. Florida State Hort. Soc. 93:120-124.

Bowcock, A.M., A. Ruiz-Linares, J. Tomfohrde, E. Minch, J.R. Kidd, and L.L. Cavalli-Sforza. 1994. High resolution of human evolutionary trees with polymorphic microsatellites. Nature 368:455-457.

Bowers, J.E., G.S. Dangl, and C.P. Meredith. 1999. Development and characterization of additional microsatellite DNA markers for grape. Amer. J. Enol. Viticult. 50:243-246. 
Bowers, J.E., G.S. Dangl, R. Vignani, and C.P. Meredith. 1996. Isolation and characterization of new polymorphic simple sequence repeat loci in grape (Vitis vinifera L.). Genome 39:628633.

Brooks, R.M. and H.P. Olmo. 1997. The Brooks and Olmo register of fruit and nut varieties. ASHS Press, Alexandria, VA.

Calenge, F. and C.E. Durel. 2006. Both stable and unstable QTLs for resistance to powdery mildew are detected in apple after four years of field assessments. Mol. Breed. 17:329-339.

Dangl, G.S., M.L. Mendum, B.H. Prins, M.A. Walker, C.P. Meredith, and C.J. Simon. 2001. Simple sequence repeat analysis of a clonally propagated species: A tool for managing a grape germplasm collection. Genome 44:432-438.

Dearing, C. 1917. Muscadine grape breeding. J. Hered. 8:409-424.

Dearing, C. 1948. New muscadine grapes. U.S. Dept. Agr. Circ. 769.

Detjen, L.R. 1919. Some F1 hybrids of Vitis rotundifolia with related species and genera. North Carolina Agr. Expt. Sta. Tech. Bull. No. 18.

Di Gaspero, G., G. Cipriani, A.-F. Adam-Blondon, and R. Testolin. 2007. Linkage maps of grapevine displaying the chromosomal locations of 420 microsatellite markers and 82 markers for R-gene candidates. Theor. Appl. Genet. 114:1249-1263.

Di Gaspero, G., E. Peterlunger, R. Testolin, K.J. Edwards, and G. Cipriani. 2000. Conservation of microsatellite loci within the genus Vitis. Theor. Appl. Genet. 101:301-308.

Doligez, A., A.-F. Adam-Blondon, G. Cipriani, G. Di Gaspero, V. Laucou, D. Merdinoglu, C.P. Meredith, S. Riaz, C. Roux, and P. This. 2006. An integrated SSR map of grapevine based on five different populations. Theor. Appl. Genet. 113:369-382.

Felsenstein, J. 2006. PHYLIP 3.6: Phylogeny inference package. 26 Mar. 2008. <http://evolution.genetics.washington.edu/phylip/ getme.html $>$.

Galet, P. 1998. Grape varieties and rootstock varieties. Oenoplurimédia, Chaintré, France.

Husmann, G.C. and C. Dearing. 1913. Muscadine grapes. U.S. Dept. Agr. Farmers' Bull. 273.

Lane, R.P. 1980. 'Triumph' muscadine grape. HortScience 15:322.

Liberty Hyde Bailey Horitorium1976. Hortus third. A concise dictionary of plants cultivated in the United States and Canada. Macmillan, New York.

Lodhi, M.A., B.I. Reisch, and N.F. Weeden. 1994. A simple and efficient method for DNA extraction from grapevine cultivars and Vitis species. Plant Mol. Biol. Rpt. 12:6-13.

Lowe, K.M. and M.A. Walker. 2006. Genetic linkage map of the interspecific grape rootstock cross Ramsey (Vitis champinii) $\times$ Riparia Gloire (Vitis riparia). Theor. Appl. Genet. 112:1582-1592.

Merdinoglu, D., G. Butterlin, L. Bevilacqua, V. Chiquet, A.-F. AdamBlondon, and S. Decroocq. 2005. Development and characterization of a large set of microsatellite markers in grapevine (Vitis vinifera L.) suitable for multiplex PCR. Mol. Breed. 15:349-366.

Minch, E. 1997. Microsat, version 1.5b. 1 Feb. 2008. <http://hpgl. stanford.edu/projects/microsat/>.

Mortensen, J.A. 1971. Breeding grapes for central Florida. HortScience 6:7-11.

Mortensen, J.A. 2001. Cultivars, p. 91-105. In: F.M. Basiouny and D.G. Himelrick (eds.). Muscadine grapes. ASHS Crop Production Series, Alexandria, VA.
Mortensen, J.A., J.W. Harris, D.L. Hopkins, and P.C. Andersen. 1994. 'Southern Home': An interspecific hybrid grape with ornamental value. HortScience 29:1371-1372.

Munson, T.V. 1909. Foundations of American grape culture. T.V. Munson and Son, Denison, TX.

National Center for Biotechnology Information. 2005. Summary of maps in uniSTS. 26 Mar. 2008. <http://www.ncbi.nlm.nih.gov/sites/ entrez? $\mathrm{db}=$ unists $\& \mathrm{cmd}=$ search\&term $=$ vitis $>$.

Nei, M. 1987. Molecular evolutionary genetics. Columbia University Press, New York.

Olmo, H.P. 1986. The potential role of (vinifera $\times$ rotundifolia) hybrids in grape variety improvement. Experientia 42:921-926.

Olmo, H.P. 1995. Grapes, p. 485-490. In: J. Smart, and M.W. Simmonds (eds.). Evolution of crop plants. 2nd ed. Longman Group, Harlow, UK.

Page, R.D.M. 1996. TreeView: An application to display phylogenetic trees on personal computers. Comput. Appl. Biosci. 12:357-358.

Park, S.D.E. 2001. Trypanotolerance in West African cattle and the population genetic effects of selection. Ph.D. thesis. Trinity College, Dublin, Ireland.

Patel, G.I. and H.P. Olmo. 1955. Cytogenetics of Vitis: I. The hybrid of $V$. vinifera $\times V$. rotundifolia. Amer. J. Bot. 42:141-159.

Pauquet, J., A. Bouquet, P. This, and A.-F. Adam-Blondon. 2001. Establishment of a local map of AFLP markers around the powdery mildew resistance gene Run 1 in grapevine and assessment of their usefulness for marker aided selection. Theor. Appl. Genet. 103:1201-1210.

Reimer, F.C. and L.R. Detjen. 1914. Breeding rotundifolia grapes: A study of transmission of character. North Carolina Agr. Expt. Sta. Tech. Bull. No. 10.

Riaz, S., G.S. Dangl, K.J. Edward, and C.P. Meredith. 2004. A microsatellite marker based framework linkage map of Vitis vinifera L. Theor. Appl. Genet. 108:864-872.

Riaz, S., A.F. Krivanek, K. Xu, and M.A. Walker. 2006. Refined mapping of the Pierce's disease resistance locus, $P d R 1$, and sex on an extended genetic map of Vitis rupestris $\times$ Vitis arizonica. Theor. Appl. Genet. 113:1317-1329.

Sefc, K.M., F. Regner, E. Turetschek, J. Glössl, and H. Steinkellner. 1999. Identification of microsatellite sequences in Vitis riparia and their applicability for genotyping of different Vitis species. Genome 42:367-373

Sneath, R.R. and R.R. Sokal. 1973. Numerical taxonomy. Freeman, San Francisco.

Thomas, M.R., P. Cain, and N.S. Scott. 1994. DNA typing of grapevines: A universal methodology and database for describing cultivars and evaluating genetic relatedness. Plant Mol. Biol. 25:939-949.

Tommasini, L., N. Yahiaoui, P. Srichumpa, and B. Keller. 2006. Development of functional molecular markers specific for seven $P m 3$ resistance alleles and their validation in the bread wheat gene pool. Theor. Appl. Genet. 114:165-175.

University of California. 2003. UC Davis College of Agriculture and Environmental Sciences Genome Facility. 26 Mar. 2008. <http:// cgf.ucdavis.edu/SequencePHP/Visitors/Pipeline/getspecie/ getspeciesaction.php?PlantGenusid $=1>$.

Walker, M.A., L.A. Lider, A.C. Goheen, and H.P. Olmo. 1991. VR O39-16. HortScience 26:1224-1225. 